\title{
Determination of PCBs in tetrachlorinated quinone using gas chromatography with electron capture detection
}

\author{
Xin-Hui Bi, Xiao-Bai Xu*, Ming-Hui Zheng, Qing-Yu Meng, Shan Fu \\ Research Center for Eco-Environment Sciences, Chinese Academy of Sciences, Beijing 100085, People's Republic of China
}

Received 9 September 1999; received in revised form 2 February 2000; accepted 10 February 2000

\begin{abstract}
A simple, sensitive method for determining polychlorinated biphenyl (PCB) congeners in industrial product 2,3,5,6-tetrachloro-1,4-benzoquinone with GC/ECD detection has been developed. The method based on liquid-liquid extraction from tetrachlorinated quinone dissolved in $N, N$-dimethylformamide was found to be efficient for the determination of the levels of the investigated pollutants. A series of extraction and purification steps were designed for the sample pretreatment. The congener specific averages of recoveries were $82-96 \%$ for Aroclor 1242 and 1254 at a total spiking level of ca. $0.4 \mu \mathrm{g} \mathrm{g}^{-1}$ sample. The reproducibilities of replicate determinations of different congeners were typically $5-19 \%$ except one with the average $13 \%$ R.S.D. $(n=3)$. This method was applied to evaluate the background levels of PCBs in tetrachloro-1,4-benzoquinone, of which the corresponding PCB levels varied from 0.014 to $1.5 \mu \mathrm{g} \mathrm{g}^{-1}$. (C) 2000 Elsevier Science B.V. All rights reserved.
\end{abstract}

Keywords: PCBs; 2,3,5,6-Tetrachloro-1,4-benzoquinone; Gas chromatography

\section{Introduction}

Polychlorinated biphenyls (PCBs) are a group of stable, persistent, lipophilic contamination compounds, which occur widely in many media and organisms including human [1-3], as they have been widely used as dielectric and heat transfer fluids, plasticizers, wax extenders and flame retardants [4]. However on account of their known potential toxicity, their industrial use in the US has been restricted since the 1970s [5], and

\footnotetext{
* Corresponding author. Tel.: + 86-10-62925511 ext. 2157; fax: + 86-10-62923563.

E-mail address: xbxuac@bj.col.com.cn (X.-B. Xu)
}

PCBs have been included in the "priority pollutants' listings implemented by the US Environmental Protection Agency (USEPA) and by the European Commission. Now these compounds have also been considered and proposed for inclusion in the priority pollutant list of the State Administration of Environmental Protection (SAEP) in China. For this reason, the level of $\mathrm{PCBs}$ in industrial products is being given more attention.

PCBs theoretically consist of 209 congeners that differ significantly in terms of their physicochemical properties, persistence and their biological activities. Studies of structure-activity relationships suggest the non-ortho PCBs such as 
PCBs 77(34-34), PCBs 126 (345-34) and PCBs 169 (345-345), substituted with chlorine atoms in both para- and at least one meta-position, and their mono-ortho analogues such as 105 (234-34), 118 (245-34), 123 (345-24), 114 (2345-4) and 167 (245$345)$ have biological properties similar to the wellknown 2,3,7,8-tetrachlorodibenzo- $p$-dioxin [4]. Therefore, congener specific analyses of PCBs in environmental samples are popular now.

The vast majority of PCBs of concern to analytical chemists are derived from commercial sources (e.g. Aroclor series and Clophen series). However, PCBs can also be produced as byproducts in a wide variety of chemical processes which contain chlorine and hydrocarbon sources. The byproduct PCBs are usually generated inadvertently and unintentionally. US rules, therefore, not only control the use of commercial mixtures such as contaminated transformer oils, but also impinge on such industrial processes as manufacture of chlorinated benzenes, vinyl chloride, chlorinated solvents (e.g. chloroform), chlorinated alkanes, which could produce PCBs as byproducts [6].

The preseparations of PCBs from environmental matrices in their analyses have been reported, largely including supercritical fluid extraction (SFE), accelerated solvent extraction (ASE), solidphase microextraction (SPME) and subcritical water extraction coupled with solid-phase microextraction [7-10] and so on. But relatively less is known for PCBs contamination in commercial and industrial products. Buchta found PCBs contamination in copper phthalocyanine pigments [11]. Rastogi found seven out of 11 printing inks investigated to contain PCBs in concentrations up to $180 \mathrm{ng} \mathrm{g}^{-1}$ [6]. The aim of this study was to develop a method for determination of PCBs and specifically to manifest the existence and magnitudes of PCBs contamination in the industrial product 2,3,5,6-tetrachloro-1,4-benzoquinone (commercial name chloranil).

Chloranil is one of the familiar quinonoids with all the four positions substituted by electron withdrawing chlorine atoms. The structure of the 2,3,5,6-tetrachloro-1,4-benzoquinone is shown in the diagram.<smiles>O=C1C(Cl)=C(Cl)C(=O)C(Cl)=C1Cl</smiles>

Because of the sufficiently high electron affinity, chloranil is widely used as the electron acceptor in electron donor-acceptor systems. In addition, it may be used as a fungicide in agriculture and a dye intermediate in industry.

\section{Experimental}

\subsection{Chemical and materials}

All reagents utilized were of 'analytical reagent' grade. The solvents used were $N, N$-dimethyformamide, dichloromethane, and hexane. They were obtained from Xinguang Chemical Plant and the Beijing Chemical Plant (Beijing, China) and redistilled in an all-glass appliance before use. Aroclor 1242 and 1254 used as the standard reference materials were obtained from Supelco Corporation. Sodium chloride and anhydrous sodium sulfate (from Beijing Shuanghuan Chemical Reagent Plant and Beijing Lihuadian Chemical Plant) were used to minimize water solubility losses and dry the organic phases. Basic aluminum oxide (100200 mesh, from the Wusi Chemical Plant of Shanghai) was used for cleaning up the samples.

Stock standard solutions of PCBs were prepared by dissolving Aroclors in hexane. A series of working composite standard solutions were prepared by combining an aliquot of each of the stock solutions and diluting the mixture with hexane. These solutions were stored in dark glass bottles at $4^{\circ} \mathrm{C}$.

2,3,5,6-Tetrachloro-1, 4-benzoquinone was obtained from a chemical factory in the north of China and stored in a glass bottle at $4^{\circ} \mathrm{C}$ before analysis.

\subsection{Instrument}

Congener-specific PCB analysis was performed on a Varian 3740A gas chromatograph (GC) eq- 
uipped with ${ }^{63} \mathrm{Ni}$ electron capture detector. The GC was fitted with a SE-54 capillary column (40 $\mathrm{m} \times 0.25 \mathrm{~mm}$ I.D. J \& W Scientific Inc., USA). The carrier gas was nitrogen at the flow rate of $17.3 \mathrm{~cm} \mathrm{~s}^{-1}$. A total of $1 \mu \mathrm{l}$ of sample was injected to the GC with splitless injection. The oven temperature was programmed as follows: the temperature was initially at $50^{\circ} \mathrm{C}$, and held for $2 \mathrm{~min}$. After injection, ramped at $4^{\circ} \mathrm{C} \min ^{-1}$ to $280^{\circ} \mathrm{C}$, and kept for $10 \mathrm{~min}$. The temperatures of the injector and detector were set at $300^{\circ} \mathrm{C}$ and $350^{\circ} \mathrm{C}$, respectively. A WDL-95 workstation (Dalian Inst. Chem. Phys, CAS, China) was utilized to control the system and for acquisition of analytical data.

\subsection{Sample preparation}

For determination of PCBs, about $5 \mathrm{~g}$ of accurately weighed fine powder of industrial tetrachlorinated quinone was dissolved with $\mathrm{N}, \mathrm{N}$ dimethyformamide. Where necessary, it was heated to help dissolution. The solution was dark brown. After cooling, the extract was transferred to a separatory funnel with $20 \mathrm{ml} N, N$-dimethyformamide, then $50 \mathrm{ml}$ hexane and $100 \mathrm{ml} \mathrm{N}, N$ dimethylformamide/2 mol $1^{-1} \mathrm{NaOH}$ solution $(1: 1, \mathrm{v}: \mathrm{v})$ was added to the funnel. After mixing and layering, the lower layer containing interfering co-extractants and residual 2,3,5,6-tetrachloro1,4-benzoquinone was removed. The upper hexane layer was washed again with $50 \mathrm{ml} 2 \mathrm{~mol}$ $1^{-1} \mathrm{NaOH}$ solution. The procedure was repeated until the $\mathrm{NaOH}$ solution layer remained colorless. The extract was then washed with $2 \% \mathrm{NaCl}$ solution, dried with $15 \mathrm{~g}$ anhydrous $\mathrm{Na}_{2} \mathrm{SO}_{4}$ packed in a $1 \mathrm{~cm} \times 10 \mathrm{~cm}$ glass column and was transferred to a K.D. apparatus for concentrating to about 1 $\mathrm{ml}$.

A cleanup was done by chromatography on basic aluminum oxide column with a layer of anhydrous $\mathrm{Na}_{2} \mathrm{SO}_{4}$. A total of $10 \mathrm{~g}$ of basic aluminum oxide was packed in a $1 \mathrm{~cm} \times 33 \mathrm{~cm}$ glass column with hexane. After the sample was concentrated as described above, it was transferred onto the basic aluminum oxide column. PCBs were eluted from the column with dichloromethane/hexane $(\mathrm{v} / \mathrm{v}, 1 / 49)$ in the first 80 $\mathrm{ml}$ fraction. The fraction was concentrated in
K.D. apparatus and under a gentle stream of nitrogen to proper volume.

\subsection{Calibration}

Standard solutions containing Aroclor mixture in hexane were prepared at seven concentration levels in the range of $0.2-8 \mathrm{mg}^{-1}$ and analyzed by GC-ECD. The compounds were identified and quantified by comparing their retention values and integrated peak areas with those of known external standards according to the previous analysis [12].

\subsection{Recovery and blank studies}

The recovery study was carried out by spiking stock solution 1.97-2.06 $\mu \mathrm{g}$ of Aroclor 1242 and 1254 into the $5 \mathrm{~g}$ solid samples analyzed, respectively, and equilibrating for $12 \mathrm{~h}$. Then the samples were prepared as described above. The background-contaminated levels were estimated with pure solvent instead of the sample by the same procedure.

\section{Results and discussion}

The blank chromatograms contained only a few insignificant peaks from background contaminants that did not interfere with PCB peaks. The identity of background contaminants was not determined and no blank correction of the results was performed.

Recoveries were calculated by dividing the analytical levels (PCB levels in the original sample itself were subtracted) with the spiked levels. In Table 1, the calculated recoveries were listed. The recoveries of the congeners eluted before PCB56/ 60 were calculated based on Aroclor 1242, and the others were on Aroclor 1254. All of the congeners in the samples were relatively good, with the average recoveries of all congeners ranging from 82 to $96 \%$, which indicated that the proposed procedure was suitable for determining PCBs in the tetrachlorinated quinoine. From Table 1, it can be seen that the recoveries of highly chlorinated biphenyls appeared somewhat better than 
those of less chlorinated biphenyls. This can be explained that the higher chlorinated biphenyls have lower volatility and less water solubility and thus lower loss from the concentration and wash steps. R.S.D. obtained were 5-19\%, except one, with the average $13 \%$. This demonstrated that the sample purification and analysis procedures were practically reproducible.

In Fig. 1, The GC chromatograms of Aroclor 1242, 1254 and a sample after pretreatment were shown in which pentachloromethyl benzene, hexachlorinated benzene and dichlorinated biphenyls

Table 1

Percent recoveries of polychlorinated biphenyls (PCBs) in the sampled product

\begin{tabular}{|c|c|c|c|c|c|}
\hline \multirow[t]{2}{*}{ IUPAC no. } & \multicolumn{3}{|c|}{ Run no. } & \multirow[t]{2}{*}{ Mean } & \multirow[t]{2}{*}{ R.S.D. } \\
\hline & $\mathrm{R}_{1}$ & $\mathrm{R}_{2}$ & $\mathrm{R}_{3}$ & & \\
\hline $18 / 17$ & 96 & 72 & 80 & 83 & 14.8 \\
\hline $16 / 32$ & 74 & 73 & 82 & 76 & 6.5 \\
\hline $26 / 25$ & 94 & 85 & 69 & 83 & 15.3 \\
\hline $31 / 28$ & 105 & 95 & 82 & 94 & 12.3 \\
\hline 33 & 66 & 77 & 82 & 75 & 10.9 \\
\hline 22 & 76 & 82 & 86 & 81 & 6.2 \\
\hline 52 & 77 & 107 & 80 & 88 & 18.8 \\
\hline 49 & 84 & 67 & 64 & 72 & 15.0 \\
\hline $47 / 48$ & 53 & 56 & 72 & 60 & 16.9 \\
\hline 44 & 89 & 106 & 89 & 95 & 10.4 \\
\hline $41 / 64$ & 80 & 98 & 86 & 88 & 10.4 \\
\hline 74 & 120 & 109 & 110 & 113 & 5.4 \\
\hline 70 & 105 & 109 & 68 & 94 & 24.0 \\
\hline 66 & 81 & 83 & 80 & 77 & 7.9 \\
\hline $56 / 60$ & 125 & 88 & 115 & 109 & 17.5 \\
\hline 101 & 91 & 97 & 77 & 88 & 11.6 \\
\hline 99 & 97 & 101 & 80 & 93 & 12.0 \\
\hline 97 & 107 & 116 & 83 & 102 & 16.7 \\
\hline 87 & 97 & 108 & 80 & 95 & 14.8 \\
\hline 85 & 96 & 101 & 82 & 93 & 10.6 \\
\hline 110 & 96 & 100 & 78 & 91 & 12.8 \\
\hline 82 & 99 & 100 & 72 & 90 & 17.6 \\
\hline $108 / 118 / 149$ & 101 & 112 & 84 & 99 & 14.2 \\
\hline 146 & 102 & 107 & 83 & 97 & 13.0 \\
\hline 153 & 115 & 117 & 88 & 107 & 15.2 \\
\hline 141 & 82 & 80 & 60 & 74 & 16.4 \\
\hline 137 & 92 & 91 & 70 & 84 & 14.7 \\
\hline 138 & 90 & 95 & 72 & 86 & 14.1 \\
\hline 128 & 105 & 115 & 80 & 100 & 18.0 \\
\hline 177 & 127 & 117 & 129 & 124 & 5.2 \\
\hline 180 & 107 & 92 & 76 & 92 & 9.8 \\
\hline 170 & 119 & 121 & 102 & 114 & 9.2 \\
\hline Average & 95 & 96 & 82 & 91 & 13 \\
\hline
\end{tabular}

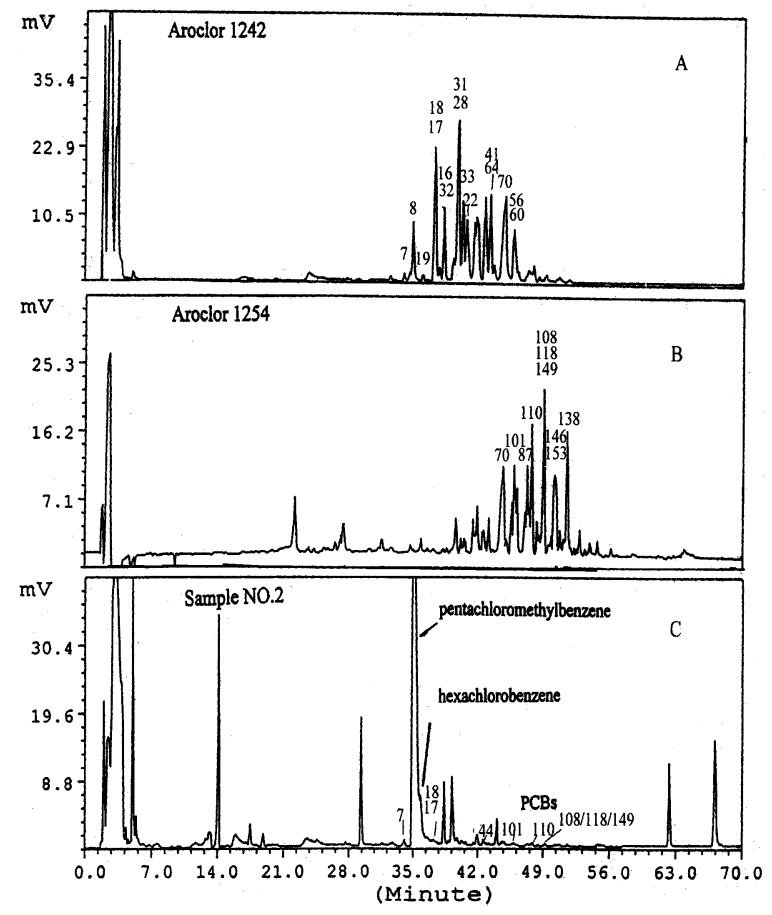

Fig. 1. GC-ECD chromatogram of aroclors (A) (B) and polychlorinated biphenyls (PCBs) (C) extracted from the tetrachlorinated quinone sample.

were confirmed by GC/MS. Because of the complexity of the compounds in industrial products and the low level of pollutant, an attempt was not made to identify other peaks in the GC chromatogram. But it was suggested that this method could also be modified and applied to the quantification of additional components such as PCDD/PCDFs and chlorobenzene if the purification condition is somewhat changed. As a matter of fact, this method developed can be used in the analyses of PCBs in the product with the similar properties as tetrachlorinated quinone.

PCB concentrations were determined by comparing the GC-ECD chromatographic peak areas to those of commercial Aroclor (1242 and 1254) standards preparation. Twenty seven peaks were detected in the samples according to their retention indexes [12], and their levels for these samples and detection limits were listed in Table 2.

Sample no. 1 had a PCB content of $1.53 \mu \mathrm{g}$ $\mathrm{g}^{-1}$, which was significantly higher than those of the other two samples. The no. 3 sample, which 
had been treated additionally through recrystallization, was found to have the lowest contamination of PCBs.

\section{Conclusion}

The method developed in this laboratory has been successfully applied to separate and determine PCB congeners in the industrial product of tetrachlorinated quinone. The average recoveries of 32 congeners in Aroclor 1242 and 1254 were $82-96 \%$. The reproducibilities of replicate determinations of different congeners were typically $5-19 \%$ except one with the average $13 \%$ R.S.D. $(n=3)$. The sample-preparation procedure seems to be effective in eliminating troublesome compounds and then producing a clean injection solution for GC-ECD analysis. The chromatographic method allowed sensitive determination of PCBs in tetrachlorinated quinone samples at the $\mathrm{ng} \mathrm{g}^{-1}$ level. The present or similar sample-preparation and analysis protocol might be also applicable to the measurement of other related compounds in tetrachlorinated quinone or to the analysis of other complex systems. Of course, further testing for more samples are definitely helpful to confirm the application of this assay developed in this paper as it has been conducted only on limited product.

Table 2

Polychlorinated biphenyls (PCBs) levels in tetrachlorinated quinone products

\begin{tabular}{|c|c|c|c|c|c|}
\hline \multirow[t]{2}{*}{ IUPAC no. } & \multirow[t]{2}{*}{ Congener } & \multicolumn{3}{|c|}{ Sample concentration $\left(\mu \mathrm{g} \mathrm{g}^{-1}\right)$} & \multirow[t]{2}{*}{ Detection limit $\left(n g g^{-1}\right)$} \\
\hline & & No. 1 & No. 2 & No. 3 & \\
\hline 7 & 24 & 0.61 & 0.014 & 0.0039 & 0.098 \\
\hline 19 & $22{ }^{\prime} 6$ & 0.065 & 0.0093 & $\mathrm{ND}^{\mathrm{a}}$ & 0.14 \\
\hline $17 / 18$ & $22^{\prime} 4 / 22^{\prime} 5$ & 0.26 & 0.0058 & 0.0011 & 0.08 \\
\hline $16 / 32$ & $22^{\prime} 3 / 24^{\prime} 6$ & 0.029 & 0.056 & 0.0012 & 0.056 \\
\hline $26 / 25$ & $23^{\prime} 5 / 23^{\prime} 4$ & 0.010 & ND & ND & 0.072 \\
\hline $31 / 28$ & $24^{\prime} 5 / 244^{\prime}$ & 0.19 & ND & ND & 0.052 \\
\hline 33 & $2 ’ 34$ & 0.019 & ND & ND & 0.067 \\
\hline 22 & $234^{\prime}$ & ND & 0.00013 & ND & 0.029 \\
\hline 45 & $22 ’ 36$ & ND & 0.0013 & ND & 0.08 \\
\hline 52 & $22^{\prime} 55^{\prime}$ & 0.084 & 0.0051 & ND & 0.077 \\
\hline 49 & $22^{\prime} 45^{\prime}$ & 0.020 & 0.0017 & 0.0018 & 0.048 \\
\hline 44 & $22{ }^{\prime} 35^{\prime}$ & 0.024 & 0.0045 & ND & 0.048 \\
\hline $37 / 42$ & $344^{\prime} / 22^{\prime} 34^{\prime}$ & 0.012 & 0.0031 & 0.0011 & 0.11 \\
\hline $41 / 64$ & $22^{\prime} 34 / 234^{\prime} 6$ & 0.006 & 0.00054 & 0.00025 & 0.048 \\
\hline 40 & $22 ’ 33 ’$ & ND & 0.0010 & 0.0013 & 0.048 \\
\hline 74 & $244^{\prime} 5$ & 0.018 & 0.00048 & ND & 0.15 \\
\hline 70 & $234^{\prime} 5$ & 0.0077 & 0.00033 & ND & 0.086 \\
\hline $56 / 60$ & $233^{\prime} 4^{\prime} / 2344^{\prime}$ & 0.014 & 0.00031 & ND & 0.032 \\
\hline 101 & $22 ’ 455^{\prime}$ & 0.043 & 0.0012 & ND & 0.16 \\
\hline 99 & $22 ’ 44^{\prime} 5$ & 0.0028 & 0.00082 & ND & 0.17 \\
\hline 97 & 22’3’45 & ND & ND & 0.0017 & 0.39 \\
\hline 87 & $222^{\prime} 345^{\prime}$ & 0.036 & 0.0014 & 0.00029 & 0.074 \\
\hline 110 & $233^{\prime} 4^{\prime} 6$ & ND & 0.0012 & ND & 0.14 \\
\hline 82 & $223^{\prime} 33^{\prime} 4$ & 0.011 & 0.0011 & ND & 0.14 \\
\hline $108 / 118 / 149$ & $233^{\prime} 45^{\prime} / 23^{\prime} 44^{\prime} 5 / 22^{\prime} 34^{\prime} 5^{\prime} 6$ & 0.053 & 0.0012 & ND & 0.16 \\
\hline 146 & $22{ }^{\prime} 34^{\prime} 55^{\prime}$ & ND & ND & 0.00092 & 0.12 \\
\hline 138 & $22{ }^{\prime} 344^{\prime} 5^{\prime}$ & 0.023 & 0.00066 & ND & 0.14 \\
\hline Sum & & 1.5 & 0.11 & 0.014 & 2.7 \\
\hline
\end{tabular}

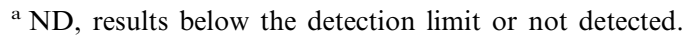




\section{Acknowledgements}

We thank Mr Shi-Qi Lu for his providing the tetrachlorinated quinone samples and Dr MingJun Piao for his helpful discussion. We are also gratefully indebted to Dr H.F. Zou of Dalian Institute of Chemical Physics, Chinese Academy of Sciences, Dalian for his providing the WDL-95 workstation. Financial support from Bureau of Resources and Environment (KZ-951-B1-209-02) and Chemistry Branch of Bureau of Basic Study, CAS are gratefully acknowledged.

\section{References}

[1] L.J. Jackson, D.E. Schindler, Environ. Sci. Technol. 30 (1996) 1861.

[2] H. Iwata, S. Tanabe, K. Ueda, R. Tatsukawa, Environ.
Sci. Technol. 29 (1995) 792.

[3] S. Safe, Toxicol. Environ. Chem. 5 (1982) 153.

[4] S. Safe, S. Bandiera, T. Sawyer, L. Robertson, L. Safe, A. Parkinson, P.E. Thomas, D.E. Ryan, L.M. Reik, W. Levin, M.A. Denomme, T. Fujita, Environ. Health Perspect. 60 (1985) 47.

[5] WHO, Geneva, Environmental Health Criteria 140, Polychlorinated Biphenyls and Terphenyls, 1993.

[6] M.D. Erickson, Analytical Chemistry of PCBs, Second Edition, CRC/Lewis, Boca Raton, FL, 1997, p. 44.

[7] W.J. Yoo, L.T. Taylor, J. AOAC Int. 80 (1997) 1336.

[8] B. Witter, W. Francke, S. Franke, Hans-D. Knauth, G. Miehlich, Chemosphere 37 (1998) 63.

[9] D.W. Potter, J. Pawilszyn, Environ. Sci. Technol. 28 (1994) 298.

[10] S.B. Hawthorne, C.B. Grabanski, K.J. Hageman, D.J. Miller, J. Chromatogr. A 814 (1998) 151.

[11] R.C. Buchta, H.F. Wyles, C.J. Hensler, F.J. Van Lenten, R.B. Westerberg, L.A. Williams, J. Chromatogr. 325 (1985) 456.

[12] S.G. Chu, X.S. Miao, X.B. Xu, J. Chromatogr. A 724 (1996) 392. 